\title{
RESSIGNIFICANDO A ESTRATÉGIA: A ABORDAGEM DA ESTRATÉGIA COMO PRÁTICA A PARTIR DAS CONTRIBUIÇÕES DA ECONOMIA EVOLUCIONÁRIA
}

\section{RESSIGNING THE STRATEGY: THE STRATEGY AS A PRACTICE APPROACH FROM THE EVOLUTIONARY ECONOMY CONTRIBUTIONS}

\author{
Eduardo Aquino Hübler \\ PPGA - Universidade Federal de Santa Catarina/UFSC \\ eduardohubler@gmail.com \\ Rosalia Aldraci Barbosa Lavarda \\ PPGA - Universidade Federal de Santa Catarina/UFSC \\ rosalia.lavarda@ufsc.br
}

Submissão: $27 / 08 / 2017$

Aprovação: 13/12/2017

\begin{abstract}
RESUMO
Este ensaio teórico visa compreender as contribuições da economia evolucionária para Estratégia como Prática ( $\operatorname{Sas} P$ ). Para tanto, apresentam-se as categorias analíticas oriundas da visão evolucionária, em particular, os conceitos de instintos, hábitos, mitos autorizados (enabling myths) e emulação (emulation) propostos por Veblen (1983), bem como, as definições de rotinas e habilidades individuais (skills), de Nelson e Winter (1982). Dessa forma, o presente ensaio teórico atende ao estabelecido por Whetten (2003) para estudos dessa natureza. Assim, a partir da abordagem da estratégia como prática, analisou-se a aderência do modelo proposto por Jarzabkowski, Balogun e Seidl (2007) às ideias evolucionárias. Dessa perspectiva, depreendem-se três proposições $(\mathrm{P})$ : [P1] as noções de rotinas e emulação auxiliam na compreensão do constructo práticas; [P2] instintos, hábitos e mitos autorizados explicam o conceito de práxis, em dado contexto temporal e espacial, haja vista o efeito de enraizamento (embeddedness) que tais aspectos exercem no âmbito da cultura organizacional e; [P3] habilidades individuais (skills) caracterizam os praticantes no processo de fazer estratégia (strategizing), sobretudo, o que, como e porque fazem, considerando-se o nível micro de análise. Por fim, apresenta-se um modelo integrador teórico para o campo da estratégia organizacional.
\end{abstract}

PALAVRAS-CHAVE: estratégia como prática, economia evolucionária, hábitos, rotinas, ensaio teórico. 


\begin{abstract}
This theoretical essay aims to understand the contributions of evolutionary economics to Strategy as Practice (SaP). In order to do so, we present the analytic categories derived from the evolutionary view, in particular the concepts of instincts, habits, enabling myths and emulation proposed by Veblen (1983), as well as the definitions of routines and skills, by Nelson and Winter (1982). Thus, the present theoretical essay complies with that established by Whetten (2003) for studies of this nature. From the approach of $S a s P$, we analyze the adherence of the model proposed by Jarzabkowski, Balogun and Seidl (2007) to the evolutionary ideas. From this perspective, we elaborate three propositions (P): [P1] the notions of routines and emulation help in the understanding of the construct practices; [P2] authoritative instincts, habits and myths explain the concept of praxis in a given temporal and spatial context, given the embeddedness that these aspects exert in the context of organizational culture; [P3] Skills characterize practitioners in the process of strategizing, especially what, how and why they do, considering the micro level of analysis. Finally, a theoretical integrative model is presented for the field of organizational strategy.
\end{abstract}

KEY-WORDS: strategy as practice, evolutionary economy, habits, routines, essay. 


\section{INTRODUÇÃO}

O campo da estratégia organizacional desenvolveu-se de modo consistente ao longo do tempo, contudo, de forma fragmentada, onde perspectivas distintas, rivais e por vezes excludentes acerca dos fatores que determinam a perfomance de dadas organizações em seus contextos específicos (Mintzberg et al, 2000; Volberda, 2004). De fato, essa fragmentação decorre, sobretudo, de diferentes visões epistemológicas sobre o que é estratégia, como ela se dá e qual seu propósito, que são antagônicas à abordagem positivista hegemônica no campo, de natureza reducionista e teleológica, entendendo a estratégia a partir de um contexto estático, onde a ação deliberada e a ênfase na maximização dos lucros seriam centrais à análise, sendo que, seu arcabouço metodológico se estabelece a partir de disciplinas oriundas das ciências naturais, tais como a física, a biologia e a matemática (Whittington, 1996, 2000, 2006).

Acerca da fragmentação no campo, apresenta-se a perspectiva de Whittington (1996; 2000) a partir de quatro possibilidades para agrupamento das diferentes linhas de pensamento estratégico tendo por base dois fatores: os resultados pretendidos (maximização dos lucros ou outros resultados, plurais) e a formação da estratégia (se deliberada ou emergente). Emergindo da análise dessas perspectivas, quatro grupos são estabelecidos: os clássicos (maximização de lucros, com a estratégia sendo tida como deliberada), os evolucionários (também voltados para a maximização dos lucros, mas entendendo a formação da estratégia como emergente), os processuais (que consideram resultados plurais e a formação da estratégia de forma emergente) e os sistêmicos (que entendem a estratégia como deliberada e voltada a uma pluralidade de objetivos que não apenas a maximização dos lucros).

De fato, Whittington $(1996 ; 2000)$ e, posteriormente, Whittington (2006) apresenta uma abordagem para a investigação da estratégia alternativa à visão dominante baseada nos pressupostos positivistas, bem como, distante dos fundamentos que caracterizam o pensamento econômico clássico, originalmente baseado em uma visão hedonista do ser humano, teleológica, com a sua racionalidade orientada ao objetivo de mitigar a dor e maximizar o prazer, além de enfatizar à ação individual, atomizada, ao invés de uma perspectiva que considere as construções decorrentes da interações sociais, de forma integrada.

Isto posto, convém evidenciar em que nível se dá a fragmentação do pensamento no âmbito da estratégia organizacional, tendo por base a visão de diferentes autores. Sobre isso, em estudo acerca das diferentes linhas de pensamento que delineiam o campo, Mintzberg et al (2000) constataram que a definição de estratégia repousava sobre dez linhas de pensamento distintas resultando em cinco definições particulares para o constructo e que são, ao invés de excludentes, complementares. Dessa forma, Mintzberg et al (2000) entendem que a estratégia pode ser definida como sendo um padrão de comportamento, um posicionamento de mercado assumido, uma perspectiva, um plano de ação e, por fim, como um truque, um engodo ou uma manobra astuciosa, sendo cada uma dessas visões apropriadas tendo por base tempo e espaço específicos. Para tanto, em um esforço de agregação, Mintzberg et al (2000) estabeleceram três grandes agrupamentos para as diferentes escolas de pensamento em estratégia, a saber, as escolas prescritivas (que estabelecem como a estratégia deve ser), as escolas descritivas (como a estratégia é) e, por fim, a escola das configurações (como diferentes dimensões estratégicas intervenientes se alinham frente a dado contexto).

De forma similar, Volberda (2004) destaca a crise no campo da estratégia e propõe estabelecer as áreas de abrangência das diferentes linhas de pensamento estratégico com base nos três componentes fundamentais dos estudos em estratégia, a saber, os problemas referentes ao campo da estratégia, as disciplinas básicas de abordagem e os instrumentos para solução desses problemas. A partir dessa perspectiva, três "escolas de síntese" se estabeleceriam: a escola das "fronteiras organizacionais", a escola das "competências 
dinâmicas" e a escola das "configurações". Para Volberda (2004), as vantagens decorrentes do estabelecimento dessas escolas de síntese consistiriam na possibilidade de continuidade, aprofundamento e direcionamento dos conhecimentos nessas três áreas temáticas que, em verdade, podem ser consideradas complementares entre si, ao invés de antagônicas.

Por seu turno, Clegg, Carter e Kornberger (2004) tecem críticas enfáticas à visão clássica dominante no campo da estratégia organizacional, indicando sua inadequação para interpretar aspectos referentes ao cotidiano do estrategista, sendo esta uma preocupação que remonta a um anseio antigo na área, onde esperava-se que fosse desvelado o que os estrategistas efetivamente fazem no seu dia a dia, em detrimento do que deveriam fazer. De fato, Clegg et al (2004) evidenciam sete falácias decorrentes do domínio da visão hegemônica no campo da gestão estratégica. São elas:

(i) a disparidade entre as fantasias gerenciais e as competências organizacionais; (ii) a disparidade entre os objetivos reais e claros e os futuros, possíveis e imprevisíveis; (iii) a disparidade entre o planejamento e a implementação; (iv) a disparidade entre a mudança planejada e a evolução emergente; (v) a disparidade entre os meios e os fins; (vi) a disparidade entre uma mente planejadora (a administração) e um corpo planejado (a organização); e, finalmente, (vii) a disparidade entre a ordem e a desordem. (CLEGG et al, 2004, p.23)

Em decorrência dessa perspectiva, Clegg et al (2004, p.26) indicam pontos de interesse para o desenvolvimento de estudos sob a perspectiva da prática, no âmbito da estratégica organizacional, contemplando categorias analíticas específicas referentes às ciências sociais, em particular, a sociologia, tais como, o "poder, a identidade profissional, os agentes não humanos, a ética, as linguagens e as instituições". Contudo, os autores entendem que a exploração desses temas demanda um arcabouço epistemológico e metodológico distinto daquele que configura o pensamento positivista nas ciências naturais.

Assim, situada a fragmentação que envolve o campo da estratégia organizacional, o foco do estudo ora proposto se lança sobre a abordagem alternativa proposta por Whittington (1996) e que consiste na estratégia como prática (Strategy as Practice, SasP). Para Whittington $(1996,2000,2006)$, em contraponto à perspectiva clássica dominante no campo, notadamente positivista, teleológica e fundada sob os pressupostos das ciências naturais, essa abordagem decorre da emergência das teorias sociais nos estudos organizacionais, a partir de um movimento conhecido como a "virada da prática" (practice turn), tendo por base autores oriundos da teoria social e que tem como disciplinas fundamentais a sociologia e a história (Whittington, 2006). Nessa linha, para o autor, a estratégia não é algo que dada organização detém ou possui, mas sim, algo que a organização faz, de modo socialmente construído, por meio da interação entre três dimensões básicas intervenientes nesse processo: a prática, a práxis e os praticantes (Whittington, 2006).

Para Jarzabkowski (2005, p.34) o "fazer estratégia" (strategizing), consiste na "habilidade astuciosa para usar, adaptar e manipular os recursos empregados para engajar-se na formação da atividade da estratégia ao longo do tempo". Essa definição traz no seu bojo a importância dos diferentes atores envolvidos no processo de formação da estratégia, onde suas idiossincrasias são determinantes ao longo das diferentes interações sociais desenvolvidas. Para Jarzabkowski, Balogun e Seidl (2007) é da intersecção entre estes três elementos que decorre o fazer estratégia ou strategizing. Contudo, a operacionalização dos constructos que integram o modelo analítico proposto por Whittington (2006) e por Jarzabkowski, Balogun e Seidl (2007) depende de conceitos e definições que demandam uma abordagem multidisciplinar. 
Dessa forma, sob uma perspectiva que contempla elementos sociológicos combinados com uma visão alternativa do campo da economia, apresenta-se a abordagem da economia institucional, orientada a investigar as diferentes instituições que condicionam as ações individuais, mas, sobretudo, as ações coletivas. Estabelecida sobre pressupostos heterodoxos, antagônicos à visão clássica acerca do pensamento econômico, a economia institucional caracteriza-se por uma visão evolucionária que se mostra relevante para a compreensão em profundidade de uma dada realidade. Portanto, é a partir da perspectiva multidisciplinar que emerge a questão de pesquisa: Como a economia evolucionária pode contribuir para o entendimento da perspectiva da Estratégia como Prática?

Basicamente, nosso propósito é trazer ao âmbito da estratégia como prática as contribuições oriundas da economia, em particular da economia institucional, caracteristicamente evolucionária, cujos constructos e categorias analíticas ou constitutivas tem o potencial de subsidiar projetos de pesquisa desenvolvidos sob a abordagem da Estratégia como Prática. Assim, o objetivo do presente ensaio teórico, de natureza eminentemente qualitativa é compreender como a economia evolucionária pode contribuir para a perspectiva da Estratégia como Prática. Nesse intuito, são apresentadas as perspectivas de Thorstein Bunde Veblen (1857-1929), considerado o fundador do campo da economia institucional e precursor do Antigo Institucionalismo americano, também denominado de institucionalismo radical (Dugger, 1988), bem como, de outros institucionalistas que atuam sob a perspectiva evolucionária, em particular, de Nelson e Winter (1982).

Logo, tendo por base a definição supracitada acerca de fazer estratégia cunhada por Jarzabkowski (2005), o presente estudo, dentro do objetivo proposto, está em conformidade com preconizado por Whetten (2003) para trabalhos dessa natureza. Para tanto, foram revisados estudos clássicos e contemporâneos acerca da abordagem da estratégia como prática, bem como, referentes à visão institucionalista evolucionária, com o foco de identificar potenciais complementariedades entre as diferentes contribuições.

Dessa forma, a partir da abordagem da estratégia como prática, analisou-se o modelo proposto por Jarzabkowski, Balogun e Seidl (2007), bem como, a aderência de conceitos oriundos das ideias de Veblen (1989) acerca dos "instintos", "hábitos", "mitos autorizados" e "emulação", assim como, a pertinência das considerações feitas por Nelson e Winter (1982) acerca das "rotinas" e habilidades individuais (skills). A partir disso, três proposições (P) são decorrentes: [P1] as noções de rotinas e emulação auxiliam na compreensão do constructo práticas, de acordo com estudos de Nelson e Winter (1982) e Veblen (1983); [P2] instintos, hábitos e mitos autorizados explicam o conceito de práxis, vigente em dado contexto temporal e espacial, haja vista o efeito de enraizamento (embeddedness) que tais aspectos exercem no âmbito da cultura organizacional e; [P3] habilidades individuais (skills) permitem caracterizar os praticantes no processo de fazer estratégia (strategizing), o que fazem, como e porque, sobretudo, considerando-se o nível micro de análise.

\section{FUNDAMENTAÇÃO TEÓRICA}

Nesse tópico são apresentadas as dimensões que integram a abordagem da Estratégia como Prática, sendo elas as práticas, a práxis e os praticantes, além do seu conceito a partir da visão de Whittington (2006) e Jarzabkowski, Balogun e Seidl (2007). A seguir, são apresentadas considerações acerca de conceitos oriundos da perspectiva econômica evolucionária de Veblen $(1983$; 2010) referentes aos instintos, hábitos, mitos autorizados, emulação, bem como, de Nelson e Winter (1982) acerca das rotinas organizacionais e das habilidades individuais, como subsídio para o modelo analítico para estudos da estratégia como prática de Jarzabkowski, Balogun e Seidl (2007). Por conseguinte, discute-se a pertinência das considerações acerca desses eixos. 


\subsection{ESTRATÉGIA COMO PRÁTICA: CONCEITOS E DEFINIÇÕES}

A partir da perspectiva da "virada da prática" (practice turn) ocorrida a partir de década de 1990, o campo da estratégia organizacional passou a questionar os pressupostos que orientavam os estudos e pesquisas em estratégia. De fato, tendo por base a teoria social, deu-se início a um movimento no sentido de abordar aspectos referentes à microdinâmica organizacional, inerentes à interação entre os diferentes atores envolvidos e suas idiossincrasias, que repercutem no processo de formação de estratégias, bem como, em suas consequências para toda a dada sociedade. Dessa forma, nessa nova orientação, surge a abordagem da estratégia como prática (strategy as practice), onde a estratégia passa a ser entendida não como algo que a organização detém, possui ou adquire, mas sim, aquilo que as pessoas constroem socialmente no âmbito intra e extra organizacional (Whittington, 1996, 2006; Jarzabkowski, 2005, 2010; Jarzabkowski, Balogun, Seidl, 2007; Johnson, Langley, Melin, Whittington, 2007).

Destarte, Jarzabkowski, Balogun e Seidl (2007) abordam o fazer estratégia (strategizing) de modo a compreender questões fundamentais para o campo, tais como, quem são os estrategistas, o que fazem e como fazem. Silva, Carrieri e Junquilho (2011) destacam a ideia da estratégia como prática social ao considerar que, sob essa abordagem, o "fazer estratégia ganha contornos sociais e políticos" (p.123). Nesse sentido, de forma conceitual, Jarzabkowski (2005) define o fazer estratégia como "a habilidade astuciosa para usar, adaptar e manipular os recursos empregados para engajar-se na formação da atividade da estratégia ao longo do tempo" (p.34, grifo nosso). Desse modo, para Jarzabkowski, Balogun e Seidl (2007) o fazer estratégia decorre da interação entre três elementos centrais aos estudos da estratégia como prática: as práticas, a práxis e os praticantes. As práticas consistem naquele conjunto de conhecimentos disseminados em dado contexto, socialmente legitimados, que repercutem no que se entende pelo know-how adquirido pela organização e que são proeminentes em suas respectivas rotinas organizacionais. Por seu turno, a práxis, expressão oriunda do grego e que significa "ação", consiste na forma como as coisas são feitas, tanto intra, como extra e mesmo inter organizacionalmente, envolvendo aspectos culturais e éticos aceitos em determinado contexto social. De fato, considera-se aqui que a práxis envolve a noção de um conjunto de atividades desenvolvidas ao longo da trajetória percorrida pela organização e aqueles aspectos de natureza psíquica que foram introjetados na cultura organizacional, com vistas a sua sobrevivência, que acabaram por se tornar rotinizados. Por fim, os praticantes são os atores diretamente envolvidos no processo de fazer estratégia e, no limite, o elo de ligação entre a pática e a práxis.

A Figura 1 ilustra o modelo analítico para pesquisa em estratégia como prática proposto pelos autores.

Figura 1 - Estrutura conceitual para análise da estratégia como prática 


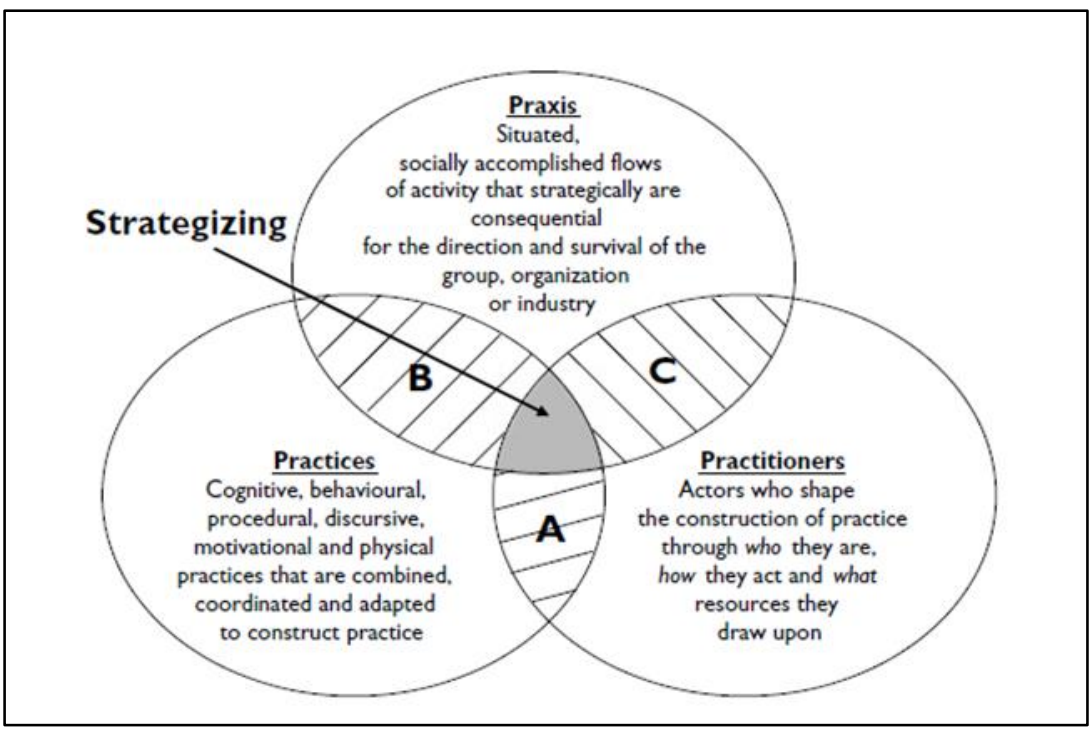

Fonte: Jarzabkowski, Balogun e Seidl (2007, p.11)

Nesse ínterim, a partir da interação entre esses três conceitos, Whittington (2006) considera que três temas essenciais emergem para que se desenvolvam estudos acerca da prática, a saber: a sociedade, as atividades atuais das pessoas "na prática" e, por fim, as habilidades e iniciativas dos atores.

Por fim, em que pese Whittington (2006) estabelecer que a abordagem da estratégia como prática deriva de uma "virada da prática" oriunda da teoria social, o presente ensaio advoga no sentido de que outros autores, notadamente do campo da economia, desenvolveram conceitos úteis para a análise no campo da estratégia organizacional. Nesse sentido, já é recorrente no campo a perspectiva evolucionária de Nelson e Winter (1982) sobre as rotinas organizacionais, contudo, a visão proposta por Veblen (1983), desenvolvida no fim do século XIX e início do século XX, acerca dos instintos e hábitos que condicionam a racionalidade econômica dos atores, teria potencial de auxiliar nos estudos de estratégia como prática, sobretudo, mas não somente, no tocante a dimensão práxis.

\subsection{A ABORDAGEM INSTITUCIONAL EVOLUCIONÁRIA DE VEBLEN: O ALCANCE DOS HÁBITOS E INSTINTOS SOBRE A RACIONALIDADE ECONÔMICA DOS AGENTES}

A economia institucional, também conhecida por Velho Institucionalismo americano em virtude de sua perspectiva histórica (e não por um eventual anacronismo), da qual Thorstein Veblen (1857-1929), economista e sociólogo americano, filho de imigrantes noruegueses, é considerado precursor, tendo também como expoentes John Roger Commons (1862-1945) e Wesley C. Mitchell (1874-1948); foi concebida sob influência da Revolução Industrial, período esse em que o capitalismo industrial se estabelecia. Em essência, a economia institucional critica os postulados que caracterizam a teoria econômica clássica, sobretudo, dada sua (a) concepção estática da economia, orientada ao equilíbrio, negligenciando seu aspecto dinâmico; (b) sua ênfase metodológica na ação individual, conduzida sob uma pretensa racionalidade substantiva, hedonista, orientada à maximizar o prazer e a mitigar a dor, bem como, (c) sua natureza teleológica, visando o incremento de seus resultados e desempenhos, em detrimento de uma abordagem holística acerca da ação coletiva, caracterizada pelas interações, conflitos e adaptações socialmente construídos ao longo do tempo e que, via de regra, nem sempre são estabelecidos sobre a lógica da melhor perfomance (Conceição, 2002; 2008a; 208b; Dugger, 1988).

De forma antagônica ao pensamento clássico, para os institucionalistas da época a 
economia deveria ser compreendida como um todo agregado, socialmente construída, ao invés de explicada por meio da ação individual, sendo que, das interações decorrentes das relações sociais ocorridas se estabeleceriam padrões coordenados de comportamento que condicionariam a ação coletiva. É da consolidação organizada dos padrões de comportamento, devidamente situada no tempo e no espaço, que os autores desse campo definem instituições. Dessa forma as instituições seriam definidas como "um conjunto de hábitos, costumes e modos de pensar cristalizados em práticas aceitas e incorporadas pela comunidade". (VEBLEN, 1983, P.XIII)

Entretanto, cabe destacar que essa noção de instituição traz em seu âmago a ideia de cumulatividade, ou seja, que as diferentes mudanças sociais ocorridas ao longo da trajetória de dada sociedade, que repercutem nos padrões de comportamento assumidos coletivamente e que, consequentemente, levam à criação, desaparecimento ou adaptação de suas instituições, condicionando as ações futuras. De fato, para Moura et al (2015), o institucionalismo de Veblen possui estreita ligação com a teoria evolucionária darwinista e a psicologia do instintohábito. Contudo, Monasterio (1998, p. 32) adverte que, apesar de Darwin permear toda a sua obra, no que se refere à mudança institucional, o institucionalismo vebleniano apresenta estreita ligação com o pensamento de Lamarck (1994). Sobre isso, o autor destaca que a visão biológica lamarckista se baseia na ideia de que as características apresentadas por determinando organismo são herdadas, de forma cumulativa, caracterizando aquilo que o pensamento vebleniano define como causação cumulativa, por meio da transmissão genética (sendo que, no campo econômico, esses genes seriam as intuições vigentes), onde uma adaptação ulterior incide sobre uma adaptação anterior, sendo esta metáfora adequada para explicar o processo de mudança institucional proposta pelo pensamento econômico evolucionário.

Mormente, destaque-se que esse processo de mudança não necessariamente repercutirá em bem-estar social e desenvolvimento social, agindo para reforçar o status quo e os interesses de grupos específicos, caracterizando aquilo que a visão vebleniana define como "teoria do absurdo", ou absurdity (Dugger, 1988; Conceição, 2000, p.98). Contudo, dado que à época a hipótese de Lamarck (1994) não foi comprovada empiricamente, fato esse que ocorreu apenas anos depois com o advento da Lei de Mendels, Veblen procurou se afastar da hipótese lamarckista, se aproximando da visão darwinista de processo evolutivo. Para Monasterio (1998, p.90), "além de ser cumulativa, outra característica de relevo do darwinismo é que as mudanças são irreversíveis". De modo a ilustrar a influência de Darwin sobre sua obra, Veblen (1983) estabelece que:

A vida do homem em sociedade, bem como a vida de outras espécies, é uma luta pela existência, e, portanto, um processo de adaptação seletiva. A evolução da estrutura social foi um processo de seleção natural das instituições. O progresso que se fez e que se vai fazendo nas instituições humanas e no caráter humano pode ser considerado, de um modo geral, uma seleção dos hábitos mentais mais aptos e um processo de adaptação forçada dos indivíduos a um ambiente que vem mudando progressivamente mediante o desenvolvimento da comunidade e a mudança das instituições sob as quais o homem vive. (VEBLEN, 1983, p.87).

Assim, se a partir da metáfora evolucionista os institucionalistas se opõe à visão clássica de estabilidade e equilíbrio ambiental, de modo análogo, a perspectiva hegemônica de que os indivíduos pautam suas ações sobre uma racionalidade dada, orientada a aumentar o prazer e minimizar a dor, bem como, sobre uma concepção teleológica, visando a maximização de resultados, é refutada por Veblen (1983). A partir da de uma abordagem metodológica interpretativista, baseada na hermenêutica e na etnografia (VEBLEN, 1983; 
MONASTERIO, 1998), Veblen (1983) desenvolveu a devida análise dos hábitos e padrões de comportamento da sociedade industrial de sua época, tendo por pressupostos que o direito de propriedade e os avanços tecnológicos decorrentes da mecanização industrial seriam vetores de uma evidente mudança na sociedade.

Por conseguinte, Veblen (1983), em obra publicada originalmente em 1899, pôs em prática uma abordagem longitudinal da caracterização da sociedade da época para evidenciar a mudança social em curso naquele momento. Considerava o autor que a propriedade privada e a tecnologia seriam responsáveis por estabelecer uma classe ociosa, em contraponto à classe trabalhadora, sendo que a constituição dessa classe ociosa decorreria do fato de que o direito de propriedade e o excedente de produção advinda do avanço tecnológico, sob a forma de lucro, estavam por estabelecer uma sociedade pecuniária, ou seja, uma sociedade cuja motivação decorria dos ganhos financeiros oriundos da posse de fatores de produção (os rentistas), com a atividade laboriosa sendo considerada indigna e tida como evidência de inferioridade social, relegada às classes subalternas, sendo que, o ócio passa a assumir a representação da superioridade das classes mais elevadas sobre a classe trabalhadora.

No limite, a propriedade privada e a própria classe ociosa são exemplos de instituições (Veblen, 1983). Contudo, o autor afasta qualquer hipótese que estabeleça, tão somente, o aspecto utilitarista e funcional como determinante tanto da condição de ociosidade das classes superiores como dos padrões de consumo dela decorrentes, abordando o que Veblen (1983, p.22) define como ócio conspícuo e consumo conspícuo, ou seja, considera que "para obter e conservar a consideração alheia não é o bastante que o homem tenha simplesmente riqueza e poder. É preciso que ele patenteie tal riqueza ou poder aos olhos de todos, porque sem prova patente não lhe dão os outros tal consideração".

Isto posto, sob inspiração evolucionária combinada com uma perspectiva psicológica, ao abordar os comportamentos consumistas no contexto da sociedade capitalista de sua época (Thorpe et al, 2015), Veblen (1983) apresenta duas categorias básicas para compreender a ação humana em dado contexto social (ou, no limite, a práxis da época), a saber, os Instintos e os Hábitos. Os Instintos são tidos como inerentes à ação humana, presentes desde a época da barbárie, caracteristicamente, orientados a um propósito específico, destacando-se dois aspectos constitutivos relevantes, segundo Monasterio (1998, p.42), a saber, sua "imutabilidade relativa e sua indeterminação (vagueness)". Segundo o autor em tela, por imutabilidade relativa entende-se a consistência dos instintos ao longo do tempo e, por indeterminação, a capacidade do ser humano em se adequar a condições ambientais distintas (p.42). Neste sentido, Silva (2010, p.295) enfatiza que o "teórico sugere a existência de instintos universais, como o da produção e o predatório ou, ainda, o da curiosidade ociosa e o paternal, que estariam presentes em toda a humanidade desde remotos tempos".

Dessa forma, os instintos são categorizados em (a) artesanal (ou a produção, ou do trabalho eficaz, orientado ao desenvolvimento e a melhoria das condições de vida da sociedade); (b) a inclinação paternal (com vistas ao bem estar social e a perpetuação da espécie); (c) a curiosidade vã (a busca pelo conhecimento, sem fins estabelecidos) e, por fim; (d) o predatório, que consiste na disposição para o conflito nas relações sociais, a competição, a busca por poder e a dominação (Veblen, 1983; Monastério, 1998; Silva, 2010). Silva (2010) adverte que no pensamento vebleniano, a definição de Instinto, em particular, difere da abordagem a partir das ciências biológicas na qual este seria uma forma de dado organismo se adaptar e adequar a um determinado contexto ambiental, de modo a garantir a sobrevivência do mais apto. Para Silva (2010), em Veblen a ação instintiva assumida pelos atores em suas relações sociais tem sim, como elemento fundamental, um caráter eminentemente teleológico. Segundo Veblen (1989) 
Ação instintiva é teleológica, consciente então, e o alcance teleológico e visado de cada propensão instintiva difere caracteristicamente de todo o resto. Os vários instintos são categorias teleológicas, e são, num uso coloquial, distinguidos e classificados sobre o terreno de seu conteúdo teleológico. [...] 'Instinto', contrariamente à ação tropismática, envolve consciência e adaptação para um fim visado. (VEBLEN, 1989, p.3-4)

Destarte, ao se afastar da perspectiva biológica acerca da noção de instinto, o pensamento evolucionário vebleniano atribui relevância à inteligência, a racionalidade do sujeito, associada à ação instintiva, essa sim, marcadamente teleológica, voltada a satisfazer interesses de poder, status e distinção no âmbito de determinada tessitura social, sendo que é deste contexto coercitivo, regulador e normativo decorrente das interações entre os sujeitos que se cristaliza a relevância das instituições (Silva, 2010).

Desse modo, além da relevância acerca da ação instintiva, destaca-se outra categoria analítica significativa para a análise social, a saber, os hábitos, subdivididos em hábitos de pensamento (disseminados e legitimados socialmente, decorrentes da reflexão acerca das experiências vividas, condicionando a práxis) que, em sociedade, consistem na noção de preconceito, bem como, no âmbito da ciência, na definição de paradigma proposto por Thomas Kuhn e; os hábitos de vida (decorrentes da experiência vivida em ações práticas cotidianas), que repercutem em uma abordagem diametralmente oposta à visão econômica clássica do "homo economicus" (Veblen, 1983; Monasterio, 1998; Silva, 2010). Segundo Silva (2010, p.298), Veblen entende o hábito como sendo a "solução para se transpor o caminho da disposição instintiva para a instituição". Daí constata-se a gênese do pensamento institucionalista vebleniano, haja vista, a partir dos hábitos ser possível compreender como determinadas práticas se consolidam em determinado arranjo social. Já Hodgson (1998, p.171) considera que, em uma visão institucionalista, o conceito de hábitos se conecta de forma crucial com a análise das instituições vigentes, haja vista, "os hábitos individuais tanto reforçarem, quanto serem reforçados, por essas instituições". Para Hodgson (1998), o hábito pode ser definido como uma tendência em grande parte não deliberativa e autoacionável de se envolver em um padrão de comportamento adotado anteriormente, bem como, autossustentáveis, caracterizando-se como o comportamento não reflexivo que surge em situações repetitivas. Nesse sentido, Conceição (2012, p.118), considera que são "os hábitos (padrões de conduta, estratégias e decisões) que estimulam o animal spirit, no sentido da constituição de instituições compatíveis com a direção em que se delineia o processo de crescimento". À guisa de conclusão, convém apresentar o esforço de síntese desenvolvido por Silva (2010) acerca das considerações veblenianas sobre instintos e hábitos:

Num esforço de síntese podemos, resumidamente, pontuar da seguinte forma o encadeamento das concepções veblenianas de instinto e hábitos. Primeiro: o instinto é influenciado por (a) forças fisiológicas ou inconscientes, (b) normas sociais e (c) pela razão, dado seu caráter teleológico; quando apontada a influência de forças fisiológicas (a), o autor pretendeu dar ao instinto um caráter geral e próprio de todo ser humano; quando apontada a influência das normas (b), o autor pretendeu caracterizar o instinto em sua natureza social. Segundo: a natureza social das práticas cotidianas consolida hábitos de vida; tais hábitos, por sua vez, transformam-se em hábitos de pensamento, institucionalizando costumes que têm a prerrogativa de alimentar as normas sociais. (SILVA, 2010, p. 301)

Com base no exposto, constata-se que a abordagem vebleniana tem em sua gênese a ideia de path dependency, a partir da sua natureza evolutiva e historicamente situada, conside- 
rando-se o caráter inexoravelmente diferenciado do processo de desenvolvimento econômico em dado contexto, bem como, aceitando que o ambiente econômico repercute em competição, divergências, conflitos e incerteza que serão mediadas pela via institucional.

Nesse contexto, como dito anteriormente, o pensamento vebleniano considera que o processo de evolução não segue uma perspectiva teleológica, tendo o potencial, inclusive, de não levar ao progresso efetivo e ao bem-estar social visando, mormente, reforçar o status quo e as estruturas de poder dominante, repercutindo em desigualdade social e atraso tecnológico. Nesse ínterim, Monasterio (1998), considera que esse processo é levado a cabo pela ação de dois instrumentos de legitimação, a saber: os enabling myths, ou mitos autorizados (p.ex.: a própria noção de mercado, que vai além da oferta e da demanda, exercendo papel coercitivo e de reprodução das estruturas de poder) e a emulation, ou emulação (que consiste na imitação de hábitos, rotinas e procedimentos de outras culturas e sociedades por parte dos indivíduos que compõem os estratos superiores de um dado tecido social e que, nesse âmbito, pressionam as esferas menos favorecidas, mais pobres) (Dugger, 1992; Monasterio, 1998; Veblen, 1983). Segundo Conceição (2000)

Os "mitos autorizados" e a "emulação" ajudam a explicar como a irracionalidade e o condicionamento social se fundem, permitindo às sociedades estratificadas se manterem unidas pela criação de uma "falsa consciência" nas populações inferiores. Tal fenômeno assegura uma não-ruptura na ordem estabelecida, impedindo os "dominados" de se rebelarem. (CONCEIÇÃO, 2000, p.98)

Da mesma forma, Clegg et al (2004, p.26) entendem que "para impressionar os stakeholders, a estratégia se tornou obrigatória como forma de criação de mitos e cerimônias".

\subsection{A IMPORTÂNCIA DAS ROTINAS ORGANIZACIONAIS PARA A ECONOMIA INSTITUCIONAL}

Nesse momento, situada a importância dos instintos e hábitos no pensamento institucionalista evolucionário, nessa mesma perspectiva cabe abrir espaço para a discussão das rotinas organizacionais propostas por Nelson e Winter (1982). Para os autores, em virtude do contexto incerto e arriscado que envolvem as escolhas empresariais e as tomadas de decisões, estas seriam tomadas com base em padrões de comportamento habituais e rotineiros, familiares aos tomadores de decisão, tal qual uma heurística, não necessariamente voltada para a maximização dos lucros, mas sim, que sejam mais "previsíveis". Dessa forma, Possas (1989) entende que os autores supracitados:

Se dão conta de que a racionalidade econômica aponta, na verdade, não para a otimização de um objetivo bem definido sob condições bem delineadas, mas para a adoção de um comportamento cauteloso e defensivo, melhor expresso no emprego de procedimentos de rotina, no processo de decisão sob condições de incerteza. (POSSAS, 1989, p.160).

De fato, pensar que as decisões acerca da busca e seleção de inovações são tomadas com base em comportamentos e normas de rotinas traz em seu bojo a perspectiva histórica e cumulativa de trajetória natural, ou seja, as decisões de busca e seleção de inovações estão condicionadas ao conhecimento técnico e práticas acumulados ao longo do tempo por agentes envolvidos nesse processo de desenvolvimento tecnológico, tais como, especialistas, técnicos, engenheiros, cientistas, dentre outros. Em consequência disso, organizações que seguem 
trajetórias tecnológicas semelhantes tendem a se agrupar.

Em tempo, essa constatação dos autores traz a perspectiva institucional para o pensamento econômico evolutivo, haja vista, a noção de "regimes tecnológicos" poder ser entendido como o proposto por Di Maggio e Powell (1983, p.149) acerca do "isomorfismo institucional", sobretudo, o isomorfismo mimético. Por isomorfismo, Di Maggio e Powell (1983, p.149) entendem que este "constitui um processo de restrição que força uma unidade em uma população a se assemelhar a outras unidades que enfrentam o mesmo conjunto de condições ambientais". Nesse sentido, no âmbito institucional os autores entendem o isomorfismo mimético como sendo a imitação de bases tecnológicas adotadas pelas organizações de modo a se adequarem às condições de incerteza estabelecidas pelo seu contexto ambiental.

Situada a dimensão institucional de Di Maggio e Powell (1983) na perspectiva evolucionária, a ênfase retorna às considerações de Nelson e Winter (1982) acerca da noção de rotinas, no âmbito do processo de mudança tecnológica ou estrutural. Nesse sentido, Possas $(1989$, p.163) considera que "sem excluir o papel fundamental e crescente da ciência no progresso técnico, e não obstante as especificidades do conhecimento necessário à atividade inventiva, trata-se de enfatizar o fato de que ele pode envolver mais arte (habilidade) e intuição do que ciência". Assim, para Nelson e Winter (1982, p.14) o conceito de rotinas se aplica a todo padrão de comportamento regular e previsível das organizações, sendo que as rotinas possuem na perspectiva evolucionária proposta o mesmo papel que os genes exercem no âmbito evolucionário biológico, ou seja, são características persistentes dos organismos e que influem em seus eventuais comportamentos assumidos (não negando que o ambiente também exerça fator de influência no comportamento apresentado). Contudo, Nelson e Winter (1982, p.17) consideram que nem todos os processos de busca e seleção de inovações são simples e consideram ser adequado distinguir as rotinas organizacionais em três classes: (a) as rotinas referentes às características operacionais (que definem o comportamento de curto prazo); (b) as rotinas de investimento e; (c) as rotinas de desenvolvimento.

Para Nelson e Winter (1982), inerente à perspectiva de rotinas organizacionais está a noção de habilidades individuais (skills) dos diferentes agentes envolvidos na organização. Os autores em tela consideram os indivíduos como entidades complexas, semelhantes às organizações, onde existem similitudes entre os conceitos de rotinas, bem como, de habilidades individuais, sendo que diferem tão somente no nível de análise. Assim, Nelson e Winter (1982, p.76) apresentam três características particulares para palavra habilidade: (1) é programática, pois envolve uma sequência de passos, onde cada passo dado desencadeia e condiciona o passo seguinte; (2) que dada performance habilidosa (skillful) é, em diversos casos, produto do conhecimento tácito e; (3) que exercitar habilidade geralmente envolve fazer diferentes escolhas.

Destarte, dentre o anteriormente exposto, em uma perspectiva evolucionária, depreende-se que os instintos, hábitos, rotinas e convenções que permeiam uma dada sociedade são determinantes na caracterização de suas instituições (e, no limite, são as próprias instituições) e estas, por conseguinte, condicionam os hábitos, rotinas e crenças das gerações que se sucedem. Dessa forma, o aparato institucional estabelecido é derivado da trajetória percorrida por dada sociedade. Nesse sentido, cabe destacar o conceito de instituições como sendo um conjunto de normas, regras, hábitos e convenções, (North, 1990; Nelson, 1995; Hodgson, 1998).

Por sua vez, Cavalieri (2013, p.61) entende que as instituições "nascem da habituação, do caráter consuetudinário que algumas das ações ou vetores de ações gerados acabam assumindo" e, desse modo, considera que as "instituições são modos de agir ou de pensar que, embora nascidos na necessidade humana de se perseguir algum fim determinado, acabam adquirindo uma dinâmica própria, isto é, tornam-se fins em si mesmas". 
Por outro lado, sem que isso repercuta em um aspecto deletério ou nocivo ao desenvolvimento do campo, constata-se que o próprio conceito de instituições é abordado de maneiras distintas e fragmentadas. Nesse ínterim, ganha robustez o conceito de instituição como sendo um conjunto de normas, regras, hábitos e convenções, com sua evolução agregando relevante, inédita e desafiadora dimensão analítica, quando inserido em estruturas sociais distintas (North, 1990; Nelson, 1995; Hodgson, 1998). Sobre essa diversidade de definições sobre o que são instituições, Conceição (2012), pondera que

A "desagregação" do termo instituição é de grande importância para a teoria econômica, notadamente na construção do nexo teórico para uma integração micro-macro. Até que ponto as decisões individuais, baseadas em crenças, expectativas e intuições podem se materializar no agregado ex post de um ambiente favorável ao crescimento autossustentado (?) e duradouro? E qual o papel das instituições nesse processo? Elas atuam no plano macro ou no plano micro? Suspeita-se que, conforme a definição ou corrente adotada, atuarão de uma ou outra forma. (CONCEIÇÃO, 2012, p.113)

Apenas de modo ilustrativo e para enfatizar sua relevância para a abordagem da estratégia como prática, cabe destacar a influência exercida pela obra de Veblen (1989) no âmbito das ciências sociais. Nesse sentido, Whittington (2006) indica que, dentre outros autores proeminentes no campo da teoria social, Pierre Bourdieu constitui a base epistemológica que fundamenta a "virada da prática" (practice turn) e que repercutiu na abordagem da estratégia como prática, sendo que, segundo Thorpe el al (2015),

\begin{abstract}
A obra do sociólogo francês Pierre Bourdieu deve a Veblen as noções de emulação pecuniária e consumo conspícuo, apesar de ele as ter modificado para se encaixarem em seu modelo teórico. Bourdieu mapeia como os indivíduos e os grupos de classes sociais estão sempre competindo entre si e se diferenciando uns dos outros, através do consumo de certos tipos de bens e serviços socialmente distintos. (THORPE el al, 2015, p.219).
\end{abstract}

Por seu turno, para Hodgson (2004, p.02) a noção de "rotina" é fundamental, sobretudo, para compreender o motivo que leva dada organização a assumir determinado comportamento e, inclusive, desvelar como se estabelecem as estratégias organizacionais. Para o autor é essencial entender como as rotinas são constituídas e alteradas, permitindo verificar como "o conhecimento é retido e transferido, para o desenvolvimento da estratégia de negócios e para a criação de políticas para incentivar práticas de negócios mais benéficas". (HODGSON, 2004, p.02).

Contudo, Hodgson (2004) enfatiza a necessidade de estabelecer a devida separação entre os conceitos de hábitos, como elementos volitivos da agência humana, de rotinas organizacionais, seu correspondente no âmbito organizacional, voltada à ação coletiva organizada. Em síntese, Hodgson (2004, p.02) considera que "para compreender o conceito de rotina, precisamos apreciar a noção de hábito, por dois motivos: (i) Rotinas operam por meio do desencadeamento do hábito individual; (ii) Rotina é a analogia organizacional do hábito individual".

Desse modo, Hodgson (2004) enfatiza a necessidade de distinção entre hábito, rotina e comportamento, destacando que os hábitos individuais e, por conseguinte as rotinas no âmbito organizacional, são predisposições, tendências, mas não, comportamento. Ou seja, o autor entende que comportamento assumido é uma consequência, enquanto o hábito, conforme concebido por Veblen, é uma propensão. 
Filósofos pragmatistas e economistas institucionais como Thorstein Veblen (1919) consideravam o hábito como uma proclividade ou capacidade adquirida, que pode ou não ser realmente expressa no comportamento atual (Hodgson, 2004). O comportamento repetido é importante para estabelecer um hábito. Mas hábito e comportamento não são os mesmos. Se adquirimos um hábito, não o usamos necessariamente o tempo todo. É uma propensão para se comportar de uma maneira particular em uma classe particular de situações. (HODGSON, 2004, p.03)

Nesse ínterim, Hodgson (2004) entende que os hábitos são construções sociais, situadas em termos temporais e espaciais, onde as condições contextuais são determinantes para que determinadas propensões comportamentais armazenadas se estabeleçam, ao invés da metáfora biológica de transmissão genética per se. Para o autor, os atores intervenientes no processo e suas idiossincrasias são determinantes para que possam encontrar respostas rápidas às demandas ambientais, preservando suas capacidades cognitivas.

Hábitos são socialmente adquiridos, ao invés de geneticamente transmitidos. Todo aprendizado e consecução de todas as habilidades dependem da aquisição de hábitos. Conhecimento e habilidade (skills) envolvem a capacidade de localizar um problema complexo e identificar rapidamente os meios para lidar com isso. Experiência e intuição são cruciais aqui. Hábitos são os meios necessários para evitar a reflexão completa sobre cada detalhe, liberando os níveis mais deliberativos da mente para mais questões estratégicas (HODGSON, 2004, p.03).

Isso posto, tendo como pressuposto que os hábitos estão contidos nas rotinas organizacionais, de modo ao interesse coletivo acomodar demandas individuais, Hodgson (2004, p.04) esclarece que "rotinas não são elas próprias hábitos: são meta-hábitos organizacionais, existentes em um substrato de indivíduos habituados em uma estrutura social. As rotinas são uma camada ontológica acima dos próprios hábitos".

Por fim, Hodgson (2004) apresenta a seguinte definição para as rotinas organizacionais, a partir de uma perspectiva mais profunda acerca da sua gênese. Para o autor, rotinas não são comportamentos, mas sim, repositórios de capacidades organizacionais $e$ habilidades individuais armazenadas que integram uma estrutura generativa de mudanças ou estabilidade.

Uma rotina é aqui definida como uma estrutura ou capacidade generativa dentro de uma organização. As rotinas são disposições organizacionais para energizar padrões condicionais de comportamento dentro de um grupo organizado de indivíduos, envolvendo respostas sequenciais a sugestões (HODGSON, 2004, p. 07).

Enfim, com base no exposto constata-se a aderência entre os conceitos de instintos, hábitos e rotinas organizacionais, oriundos da economia institucional, para auxiliar a compreensão acerca dos elementos constituintes da abordagem da Estratégia como Prática $(\operatorname{Sas} P)$. Nesse intuito, as noções de instintos e hábitos, assim como a ideia dos mitos autorizados, podem compor categorias ou elementos constitutivos de análise que permitam 
compreender, sobretudo, os elementos práxis e praticantes, enquanto as noções de rotinas, bem como, emulações, tem o potencial de auxiliar no entendimento do conceito de práticas, adotados na abordagem da $\operatorname{Sas} P$. A seção seguinte apresenta o modelo integrativo que reúne as duas bases teóricas em análise.

\section{ANÁLISE E DISCUSSÃO DOS RESULTADOS: ESTRATÉGIA COMO PRÁTICA E ECONOMIA INSTITUCIONAL EVOLUCIONÁRIA - PROPOSTA DE MODELO INTEGRATIVO TEÓRICO}

No tópico que segue apresentamos a proposta de um modelo teórico com vistas a aproximação da economia institucional com a abordagem da estratégia como prática seguindo orientações de Whetten (2003), ao propor blocos de construção para o desenvolvimento de uma contribuição teórica.

Como base na revisão apresentada, neste momento se faz pertinente a devida aproximação entre a abordagem da Estratégia como Prática e a perspectiva evolucionária da economia institucional. Neste sentido, não se pretende desenvolver esforço de síntese entre as duas visões, mas sim, integrá-las em um modelo que permita desenvolver uma agenda de pesquisa no âmbito da estratégia organizacional. Dessa forma, a Figura 2 ilustra essa convergência entre os conceitos apresentados.

Nesse sentido, tendo por base o modelo proposto na Figura 1 que apresentou a estrutura conceitual para análise da estratégia como prática de Jarzabkowski, Balogun e Seidl (2007), o modelo integrativo elaborado na Figura 2 considera que os conceitos de rotinas (Nelson e Winter, 1982; Hodgson, 2004) e emulação (Veblen, 1982) são aderentes à definição de práticas proposta por Jarzabkowski, Balogun e Seidl (2007, p.11) quando estes as descrevem como sendo aquele conjunto de aspectos "cognitivos, comportamentais, discursivos, motivacionais e experimentais que são combinados, coordenados e adaptados para construir a prática".

Da mesma forma, quando os autores apresentam a práxis como sendo "situada; fluxo de atividades socialmente construídas que estrategicamente são consequentes para a direção e sobrevivência do grupo, da organização ou do setor industrial ao qual pertencem", percebe-se a aderência com os conceitos de hábitos, tanto de vida, quanto de pensamento, bem como, com a noção de mitos autorizados (enabling myths) oriundos do pensamento vebleniano, orientados para legitimação das escolhas realizadas.

Figura 2 - Modelo Integrativo entre a abordagem da Estratégia como Prática e a Economia Institucional

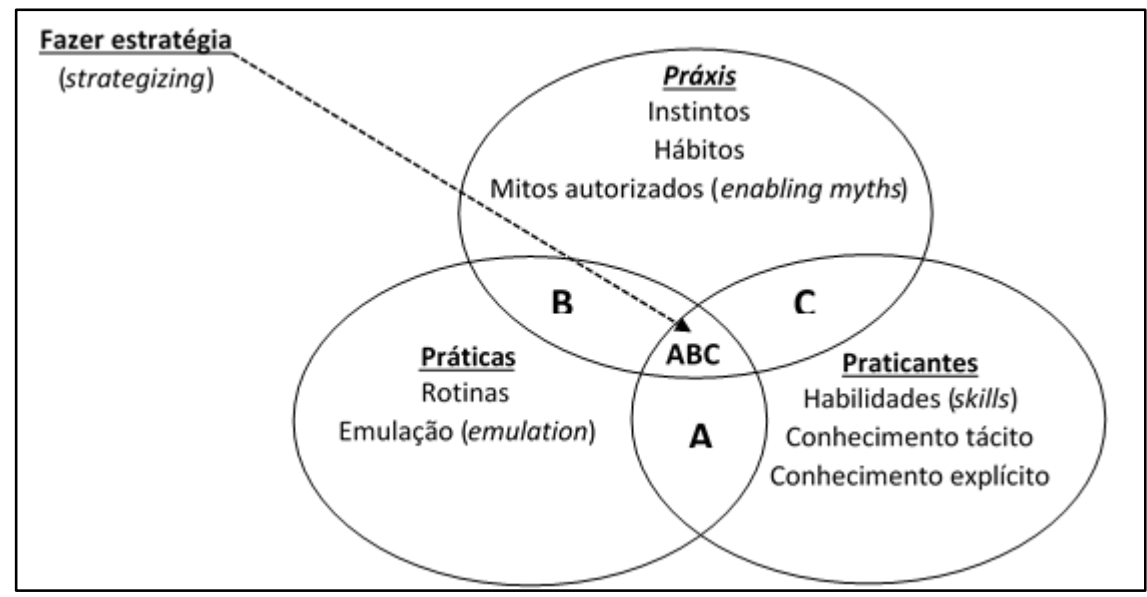

Fonte: elaboração própria

Por fim, a definição de praticantes proposta por Jarzabkowski, Balogun e Seidl (2007, 
p.11) como sendo aqueles "atores que moldam a construção da prática por meio de quem são, como agem e que recursos utilizam", permite a convergência para o conceito de habilidades individuais (skills) propostos por Nelson e Winter (1982), além de guardar coerência com a ideia de conhecimento tácito, informal e decorrente das experiências vividas pelos atores ao longo da vida, bem como, tal definição remete, também, à pertinência da ideia de conhecimento explícito, formal e disseminado organizacionalmente (Nonaka e Takeuchi, 1995).

Cabe reiterar a visão de Jarzabkowski, Balogun e Seidl (2007) que consideram o fazer estratégia (strategizing) como decorrente da intersecção entre seus três elementos constitutivos de seu modelo. Sob essa perspectiva, a análise realizada isoladamente acerca de um de seus elementos, assim como, a relação identificada entre apenas dois de seus elementos intervenientes, pode não ser suficiente para uma compreensão holística quanto ao processo de strategizing. Da mesma forma, o modelo integrativo teórico proposto também considera que compreender o fazer estratégia decorre da devida análise da intersecção entre os conceitos de instintos, hábitos, rotinas, mitos autorizados e emulação, assim como, das habilidades individuais.

Assim, com o propósito de trazer ao âmbito da estratégia organizacional as contribuições oriundas da economia, em particular da economia institucional, caracteristicamente evolucionária, cujos constructos e categorias analíticas tem o potencial de subsidiar projetos de pesquisa desenvolvidos sob a abordagem da Estratégia como Prática, pretendeu-se responder a seguinte questão de pesquisa: Como a economia evolucionária pode contribuir para o entendimento da perspectiva da Estratégia-como-Prática? Para tanto, a partir da revisão da literatura emergiram três proposições $(\mathrm{P})$ particulares e relacionadas:

[P1] as noções de rotinas e emulação auxiliam na compreensão do constructo práticas, para a qual foi encontrado respaldo nos estudos de Nelson e Winter (1982), Veblen (1983) e Hodgson (2004);

[P2] instintos, hábitos e mitos autorizados explicam o conceito de práxis, vigente em dado contexto temporal e espacial, haja vista o efeito de enraizamento (embeddedness) que tais aspectos exercem no âmbito da cultura organizacional e;

[P3] habilidades individuais (skills) permitem caracterizar os praticantes no processo de fazer estratégia (strategizing), o que fazem, como e porque, sobretudo, considerando-se o nível micro de análise.

Dessa forma, em que pese a ênfase dada por Whittington (2006) quanto a importância de autores proeminentes no campo das ciências sociais, entende-se que as proposições apresentadas aqui, a partir das perspectivas oriundas da visão evolucionária vebleniana, considerada precursora do pensamento econômico institucionalista e notadamente antagônica em relação aos pressupostos da economia clássica, tem o potencial de dar substância às categorias analíticas que integram o modelo proposto por Jarzabkowski, Balogun e Seidl (2007), a saber, a prática, a práxis e os praticantes. Nesse sentido, ao incorporar àquele modelo os conceitos de instintos, hábitos, mitos autorizados (enabling myths) e emulação (emulation), oriundos do pensamento vebleniano, bem como, os conceitos de rotinas e habilidades individuais (skills), decorrentes de Nelson e Winter (1982), entende-se que o presente estudo contribui para a pesquisa no campo da estratégia organizacional, sobretudo, ao propor um modelo integrativo entre as abordagens consideradas.

\section{CONSIDERAÇÕES FINAIS}

O presente trabalho, dentro do objetivo proposto de compreender como a economia evolucionária pode contribuir para a perspectiva da Estratégia como Prática, pretendeu evidenciar a pertinência da economia institucional com vistas a constituir uma agenda de pesquisa no âmbito da estratégia organizacional, a partir das ideias de Veblen $(1983 ; 1989)$ 
acerca dos "instintos", "hábitos", "mitos autorizados" e "emulação", além daquelas apresentadas por Nelson e Winter (1982) acerca das "rotinas", bem como, das habilidades individuais (skills). Mormente, procurou-se apresentar as contribuições decorrentes do pensamento institucionalista evolucionário para a abordagem da estratégia como prática, entendendo ser esta uma linha analítica alternativa àquela preconizada pela visão clássica no âmbito do campo da estratégia organizacional.

Dessa forma, tendo por base epistemológica os pressupostos oriundos da teoria social, a estratégia como prática surgiu como abordagem alternativa para análise da estratégia, de forma coerente com o preconizado pelo movimento conhecido como "virada da prática" (practice turn) (Whittington, 2006). Assim, tendo em mente a estratégia como algo que as pessoas fazem, antes de algo que a organização tem (Whittington, 1996, 2006), compreender a complexidade decorrente das diversas interações sociais em curso torna-se área substantiva para o estudo e pesquisa em estratégia como prática.

Mormente, o presente estudo contribui para a pesquisa no campo da estratégia organizacional, em especial, ao propor um modelo integrativo entre as abordagens da estratégia como prática e a visão econômica evolucionaria, de modo que viabilize a operacionalização do modelo proposto por Jarzabkowski, Balogun e Seidl (2007).

Contudo, a limitação do estudo ora realizado recai sobre seu alcance teórico, cabendo sugerir a realização de pesquisas empíricas que atestem a robustez do modelo proposto para a compreensão do processo de fazer estratégia nas organizações, entendendo-se, assim, a estratégia como prática socialmente construída, requerendo uma abordagem notadamente holística e não fragmentada.

Destarte, uma agenda de pesquisa a partir da abordagem da estratégia como prática, com base nas perspectivas da economia institucional, é coerente com o proposto por Clegg, Carter e Kornberger (2004, p.26) acerca da viabilização de estudos sobre dimensões analíticas, tais como, "poder, a identidade profissional, os agentes não humanos, a ética, as linguagens e as instituições". Nesse sentido, a partir de uma perspectiva sociológica, Clegg et al (2004) destacam a importância de aprofundar a compreensão sobre as instituições ao considerar que a "teoria neo-institucionalista pode nos dizer muito sobre as práticas isomórficas do campo da estratégia. Uma das principais contribuições do neo-institucionalismo tem sido dirigir as atenções para a importância que a "legitimidade" ocupa na vida organizacional" (CLEGG et al, 2004).

Da mesma forma, a partir da exposição feita entende-se que a abordagem institucionalista oriunda do pensamento vebleniano permite aprofundar a compreensão acerca da estratégia organizacional, entendendo-se essa como um fenômeno organizacional, sobretudo, por não restringir a análise ao nível macro, mas sim, desenvolver um movimento recursivo entre a agência humana e suas idiossincrasias (nível micro) e as estrutura normativa que caracteriza o contexto organizacional (nível macro). Assim, importa compreender como o movimento recursivo entre os hábitos dos diferentes atores (nível micro) que condicionam (e são condicionados) as práticas e práxis caracterizam as rotinas organizacionais (nível macro), evidenciando seus aspectos dinâmicos e estáticos, se apresenta relevante. 


\section{REFERÊNCIAS}

ALBINI J.; GONÇALVES, C.A.; CARRIERI, A.; MUNIZ, R. Estratégia como Prática: uma proposta de síntese. Revista Portuguesa e Brasileira de Gestão, 2010.

CAVALIERI, M. A. R. O surgimento do institucionalismo norte-americano de Thorstein Veblen: economia política, tempo e lugar. Economia e Sociedade, 2013.

CLEGG, S.; CARTER, C.; KORNBERGER, M. A. "máquina estratégica": fundamentos epistemológicos e desenvolvimentos em curso. Revista de Administração de Empresas, v.4, n.44, 2004.

CONCEIÇÃO, O. Instituições, crescimento e mudança na ótica institucionalista. Porto Alegre: Fundação de Economia e Estatística Siegfried Emanuel Heuser, 2002.

A dimensão institucional do processo de crescimento econômico: inovações e mudanças institucionais, rotinas e tecnologia social. Campinas. Economia e Sociedade, v.7,n. 1, p.85-105, 2008a.

Além da Transação: Uma Comparação do Pensamento dos Institucionalistas com os Evolucionários e Pós-Keynesianos. Porto Alegre: Fundação de Economia e Estatística Siegfried Emanuel Heuser, 2008b.

. Há compatibilidade entre a "tecnologia social" de Nelson e a "causalidade vebleniana" de Hodgson? Revista de Economia Política, v.32, n.1, p.109-127, 2012.

DI MAGGIO, P.J; POWELL, W.W. The iron cage revisited: institutional isomorphism and colletive rationality in organizational fields. American Sociological Review, v.48, n.2, p.147$160,1983$.

DUGGER, W.M. Radical Institucionalism: basic concepts. Review of Radical Political Economics, v.20, n.1, p.1-20, 1988.

Underground economics: a decade of institucionalist dissent. M. E. Sharp, inc. London, 1992.

FARJOUN, M. Towards an organic perspective on strategy. Strategic Management Journal, v.23, n.7, p.561-594, 2002.

HODGSON, G. The approach of institutional economics. Journal of Economic Literature, XXXVI, v. 36, p.166-192, 1998.

HODGSON, G. The evolution of institutions: an agenda for future theoretical research. Springer. Constitutional Political Economy, v.13, p.111-127, 2002.

HODGSON, G. The concept of a routine. In: The Handbook of organizational routines / Markus Becker, 2004.

JARZABKOWSI, P. Activity theory approaches to studying strategy as practice. IN: Cambridge handbook of strategy as practice. Cambridge: Cambridge University Press, 2010.

JARZABKOWSI, P.; BALOGUN, J.; SEIDL, D. Strategizing:The challenges of a practice perspective. Human Relations, v.60, n.1, p.5-27, 2007.

JOHNSON, G. LANGLEY, A.; MELIN, L; WHITTINGTON, R. Strategy as practice: research directions and resources. Cambridge, Cambridge University Press, 2007.

LAMARCK, J.B. Philosophie zoologique. Paris: Flammarion, 1994.

MACHADO, F.O. Strategy as Pratice and organizational routines: a start point to innovate. São Paulo. International Journal of Innovation, v.2, n.2, 2014.

MINTZBERG, H., AHLSTRAND, B.; LAMPEL, J. Safári de estratégia: um roteiro pela selva do planejamento estratégico. Porto Alegre: Bookman, 2000.

MONASTÉRIO, L. M. Guia para Veblen: um estudo acerca da Economia Evolucionária. Pelotas: EDUFPEL, 1998. 
MOURA, A. C.; Brites, M. ; Zucco, V.; Marin, S. R. Instintos e hábitos do pensamento como fatores de desenvolvimento: releitura a partir de Thorstein Veblen. In: IX Encontro de Economia Catarinense, Chapecó. Políticas públicas e desenvolvimento regional, 2015.

NELSON, R.; WINTER, S. An evolutionary theory of economics change. Cambridge. Harvard University Press, 1982.

NONAKA, I.; TAKEUCHI, H. The knowledge-creating company. Oxford, New York. Oxford University Press, 1995.

POSSAS, M. L. Em direção a um paradigma microdinâmico: a abordagem neoschumpeteriana. In: AMADEO, E. J. (Org) Ensaios sobre economia política moderna: teoria e história do pensamento econômico. São Paulo: Marco Zero, 1989.

SILVA, V. L. Fundamentos do institucionalismo na teoria social de Thorstein Veblen. Política \& Sociedade, 2010.

SILVA, A.R L.; CARRIERI, A. DE P.; JUNQUILHO, G. S. A estratégia como prática social nas organizações: articulações entre representações sociais, estratégias e táticas cotidianas.

São Paulo. Revista de Administração, v.46, n.2, p.122-134, 2011.

THORPEN, C.; YUILL, C.; HOBBS, M.; TODD, M.; TOMLEY, S. WEEKS, M. O livro da sociologia / ilustração James Graham; tradução Rafael Longo. São Paulo: Globo Livros, 2015.

VEBLEN, T.B. The Theory of Business Enterprise (1 edt: 1904). New York: Charles Scribner's Sons, 1932.

A teoria da classe ociosa: um estudo econômico das instituições / Thorstein Veblen; São Paulo: Abril Cultural. (Os Economistas), 1983.

Why is economics not an evolutionary science? Originally published as

Veblen, T. (1898). "Why is economics not an evolutionary science?," Quarterly Journal of Economics, v.12, n.4, p.373-397. Reprinted with kind permission, 2010.

VOLBERDA, H. W. Crise em estratégia: fragmentação, integração ou síntese. RAE: Revista de administração de empresas, v.44, n.4, p.32-43, 2004.

WHETTEN, D.A. O que constitui uma contribuição teórica?. RAE: Revista de Administração de Empresas. v.43, n.3, p. 69-73, 2003.

WHITTINGTON, R. O que é estratégia. São Paulo: Pioneira Thomson Learning, 2002. . Strategy as practice. (1996). Long Range Planning, v.29, n.5, 1996. Completing the practice turn in strategy research. Organization Studies, v.27, n.5, p.613-634, 2006. 